\title{
AGE AND PROFICIENCY IN FOREIGN LANGUAGE ANXIETY
}

\author{
IDADE E PROFICIÊNCIA NA ANSIEDADE EM LÍNGUA ESTRANGEIRA
}

\author{
Rafael Dutra ${ }^{111}$ \\ Ingrid Finger ${ }^{112}$
}

\begin{abstract}
This study aimed to investigate how proficiency and age are related to Foreign Language Anxiety (FLA). A total of 88 teenagers and adults with different levels of proficiency answered the Language History Questionnaire and the Foreign Language Classroom Anxiety Scale. The analyses revealed (1) a significant negative correlation between the participants' mean self-assessed proficiency and their level of FLA; and (2) a significant positive correlation between the participants' age and their level of FLA. In other words, the lower the proficiency level, the higher the participants' anxiety level. In addition to that, the older the participant, the higher his anxiety level. The results of the study suggest that Foreign Language Anxiety seems to be related to both proficiency level and learner age. Such results are discussed in light of previous investigations in the field of Applied Linguistics.
\end{abstract}

Keywords: Foreign language anxiety; proficiency; age.

RESUMO: Este estudo investigou como proficiência e idade estão relacionadas à Ansiedade em Língua Estrangeira. Para isso, um total de 88 participantes adolescentes e adultos com diferentes níveis de proficiência responderam a um Questionário de Histórico da Linguagem e à Foreign Language Classroom Anxiety Scale. A análise dos dados revelou (1) uma correlação significativa negativa entre a média de proficiência autoavaliada e o nível de ansiedade dos participantes; e (2) uma correlação significativa positiva entre a idade dos participantes e o seu nível de ansiedade. Em outras palavras, no caso dos participantes testados neste estudo, quanto menor o nível de proficiência, maior o nível de ansiedade demonstrado através das respostas na escala. Além disso, quanto maior a idade dos participantes, maior foi o seu nível de ansiedade. Os resultados obtidos, portanto, sugerem que a ansiedade em língua estrangeira parece estar relacionada tanto à proficiência quanto à idade do aprendiz. Tais resultados são discutidos à luz de pesquisas anteriores na área de Linguística Aplicada.

Palavras-chave: Ansiedade no aprendizado de língua estrangeira; proficiência; idade.

\section{Introduction}

Emotions are an essential part of our lives and affect our ideas and behavior. They are so common and intrinsic to the human being that one could barely give an exhaustive definition of what they are. Our feelings regulate our behavior in all aspects of life, including when we try to learn something new, such as driving, dancing, new tasks or new jobs. Likewise, emotions play a significant role when one decides to learn a foreign language. The development of foreign language may trigger both positive and negative feelings, which leads us to questions such as how teachers should respond to the arousal of emotions - particularly the negative ones - during foreign language classes.

The initial work on the role emotions play in foreign language learning was developed by Gardner \& Lambert (1972) and focused mainly on the role of attitudes and motivation. The authors' main claim was that motivated students develop positive attitudes that foster their language development. However, learning a new language can be very difficult for some individuals and this may trigger negative emotions. A very recurring negative emotion that has received particular attention from researchers is foreign language anxiety (therefore, FLA), since in foreign language classrooms, students might unconsciously create barriers to their learning process, demonstrating fear and concerns about their performance in the target language and about the level of success they expect to achieve (Horwitz et al., 1986; Dewaele, 2002; Dewaele et al., 2016;

\footnotetext{
${ }^{111}$ Master student in Psycholinguistics at the Federal University of Rio Grande do Sul.

${ }_{112}$ Ph.D. in Linguistics (Pontifical Catholic University of Rio Grande do Sul - PUCRS). Professor at the Federal University of Rio Grande do Sul.
} 
Dewaele, 2017; Dewaele et al., 2017; MacIntyre, 2017). Horwitz et al. (1986) highlight the importance of identifying anxiety in students in language classes due to the tremendous impact anxiety feelings may have in the language learning process.

Even though language teachers often follow specific methodologies, these methodologies do not normally include suggestions on how to deal with FLA in the classroom. Without training and support, teachers may face complicated situations when dealing with anxious learners. Students themselves very often report that they feel like they will never learn a new language. They also frequently say things such as "I can understand, but when I have to speak I feel stuck!" or "I cannot find the right words to say!" or else "I'm afraid to speak in front of other people." Usually these same students know how to express the ideas they want to communicate, but they get extremely nervous and uncomfortable with the fact that they need to communicate in the foreign language and end up not being able to speak. These negative emotions can be a problem and an obstacle in the learning process. Therefore, we argue that expanding our knowledge on the role FLA may play in language development is a very important tool for language teachers and may shed light on the methodological decisions they make every day.

Previous studies have shown the role emotions play in the learning process and have demonstrated that there are certain variables that trigger FLA. For instance, Horwitz et al. (1986) argue that people who are overall anxious are more likely to demonstrate anxiety related behavior in foreign language classes too. Another study carried out by Dewaele et al. (2016) found out that female learners experience more FLA - as well as enjoyment in class - in comparison to male students. Also, several studies about the role of emotions in our lives have also showed that they affect our cognition. According to López \& Aguilar (2013), emotions can even influence student's decision related to keeping on with the studies and, once language teachers are aware of that, they might develop better approaches to help increase rapport with the students. Similarly, Frenzel (2007, apud Khajavy, 2017) also studied the effects of emotions in the learning process and credited anxiety as an impediment for student's communication practice. Different reasons have been considered triggers for anxiety, but not much attention in the literature, however, has been given to how age and proficiency are related to FLA, which are the independent variables explored in the present study.

Within this context, this study aims to investigate whether age and proficiency affect FLA. In order to do so, English learners were invited to answer the Foreign Language Classroom Anxiety Scale (hereafter called FLCAS), created by Horwitz et al. (1986), a scale used to measure the participants' anxiety levels related to English learning. A Language History Questionnaire (hereafter called LHQ) was also used to provide background about participants' use and knowledge of the English language and additional personal information such as age, gender and history of language study. Additional information regarding the study is provided in the Methods section.

This article is organized as follows. After this brief introduction, the theoretical background that reviews emotions in foreign language development and anxiety, in particular, is presented, followed by a description of the methods used in the investigation reported here. After that, the results and discussion are presented. This article ends with the final considerations, where some pedagogical implications derived from this study are discussed.

\section{Literature review}

\subsection{The role of emotions in language learning}

According to Ismail (2015), teachers have given increased attention to the cognitive aspects of language learning sometimes neglecting how affect interferes with such learning. The author emphasizes, however, that emotions play an important role in the learning process. In a study with 315 Saudi EFL learners of English Language about emotions, such as anger, anxiety, enjoyment, 
hope, hopelessness, pride, boredom and shame, in an academic environment, the researcher found that positive and negative class emotions play a significant part in the student's outcomes. His study followed a paper by Frenzel (2007, apud Khajavy, 2017), who claims that emotions affect the learning process by arguing that positive emotions "are influential factors in student's psychological well-being" (p. 6) and that they help students to achieve better results. On the other hand, when students have anxiety - which is a negative emotion - concerning the language instruction, language acquisition may become a tough goal.

FL anxiety has been defined as "worry and negative emotional reaction aroused when learning or using a second language" (MacIntyre, 1999, p.27). Foreign language classrooms can be full of anxiety-provoking situations (Horwitz et al., 1986; Khodadady \& Khajavy, 2013; Young, 1991), especially when language learners must communicate in a foreign language. It has been found that communication anxiety is one of the main obstacles to fostering willingness to communicate (Peng \& Woodrow, 2010; Khajavy et al., 2016; MacIntyre, Baker, Clément \& Donovan, 1996) (Khajavy, 2017, p. 6)

Ideally, the classroom should be a place with a good atmosphere, so negative emotions such as tension and anxiety would not easily emerge. According to Dewaele and Mercer (2018), students' and teachers' emotions and motivation are linked. The atmosphere in the classroom can be negatively affected by the teacher's attitudes. It is not only the students, therefore, who should be positive regarding the process of learning a new language. If teachers do not demonstrate positive emotions towards the process, students are likely to experience bad emotions as well. Dewaele and Mercer (2018) also argue that "teacher attitudes towards their students are also reflected in the emotions that teachers experience and express both consciously and unconsciously in their behaviours in class." (p. 181). Thus, they argue, it is imperative that teachers try to establish a good rapport with the learners.

According to López \& Aguilar (2013), it is very common for language learners to have bad experiences during their learning process. Many students report having problems with previous language teachers and attribute their difficulties to such experiences. According to the authors,

if a student, for example, has had very bad learning experiences which he or she attributes to his or her capacities, he or she might not be willing to participate in any learning activity again because he or she considers that the cause of failure is something he or she cannot change (his or her cognitive ability); however, if a learner considers that the reason for failure is that he or she did not make his or her best effort, then he or she could go into a new learning situation with the disposition to make his or her best effort so he or she can have better results this time (p. 111).

By the same token, Fredrickson (2004) states that positive emotions improve cognition and attention. Moreover, the author argues, they expand people's attention, help undo persistent negative emotions, fuel psychological resiliency, build personal resources and improve psychological and physical well-being. According to Ismail (2015), taking in consideration students' emotions "should be an aim of education" (p. 30), and teachers should talk about it with their students because this could provide more enjoyment in class.

\subsection{Anxiety}

One may think anxiety is a problem of the modern world. This is probably because it is nowadays much easier to notice how anxiety affects us in our daily lives. The modern pace of life 
that technology has provided us with makes everything happen faster. We are surrounded by loads of information, work, concerns, problems, and all those things often suffocate us. It seems like everyone is always running out of time to handle all the obligations imposed on them, and high levels of anxiety affect individuals worldwide. Although many people report suffering from it, they are not necessarily aware of what anxiety is nor seem able to provide a sound definition for it.

The first writings that mention the feeling of anxiety date back to the Greeks and Romans. According to Silverman and Field (2011), in the past, anxiety in children was seen as vulnerability. It was only in the second half of the nineteenth century that anxiety in children acquired the status of a disorder. The first one to regard anxiety as a mental illness was Emminghaus (1887) in his book Anomalies of the Feelings. According to Emminghaus (1887, apud Silverman and Field, 2011, p. 15), anxiety is a pathology and has no recognizable cause:

In his systematic discussion of symptomatology in child psychiatry, Anomalies of the Feelings, Emminghaus (1887) also became the first to afford anxiety a significant role in mental illness. He regarded anxiety, cowardice, and nervousness as pathological only "if they were present as new behavior in the child in addition to other signs of a psychic disorder". (Silverman and Field, 2011, p. 15)

When we use the word 'anxiety', we may be referring to an emotion related to how we are feeling in a particular moment or situation because of bad or good events happening in our lives. Anxiety can be classified into a state or a trait. According to Oxford (1999), if language anxiety starts as isolated episodes when students need to perform in the target language, for instance, it is just a passing state. However, if episodes of anxiety become recurrent, language anxiety becomes a lasting trait. In addition, anxiety can mean a number of things, from a momentary emotion to a disorder. According to the Diagnostic and Statistical Manual of Mental Disorders (DSM-5), anxiety is, in fact, an umbrella term and there are different kinds of disorders related to it. The one that best seems to apply to language instruction is the so-called Generalized Anxiety Disorder, described in the DSM-5 as "excessive anxiety and worry (apprehensive expectation) about a number of events or activities" (p. 222). Likewise, Barlow (2002, apud Craske et al, 2009) claims that anxiety is a mood state when someone thinks about the future and is concerned about the outcome, having in mind that negative events are about to happen. Another study made by Craske et al (2009) also uses Barlow's definition. The author claims that

This view of human fear and anxiety is comparable to the animal predatory imminence continuum. That is, anxiety corresponds to an animal's state during a potential predatory attack and fear corresponds to an animal's state during predator contact or imminent contact. (Craske et al., 2009, p. 1067)

As noted above, some special attention has been given to the matter, and the construct of anxiety has changed definitions throughout history. Anxiety can also be a complication in the process of learning a new language. According to Oxford (1999), language anxiety is one of the most common problems learners face during the learning process. Therefore, it is key to improve our understanding of the relationship between anxiety and foreign language learning, a topic that will be discussed next.

\subsection{Foreign Language Anxiety (FLA)}

Research investigating FLA started in the seventies. MacIntyre (2017) presents three broad approaches to Language Anxiety research, which are the Confounded Phase, the Specialized Approach, and the Dynamic Approach. During the Confounded Phase, it was difficult for 
researchers to establish a relation between the construct of anxiety and the process of learning languages. According to the author, there were many kinds of measures for research studies related to anxiety, but none of them specific to the field of language learning, even though some scholars still claimed that anxiety interfered in students' motivation.

All of these types of measures were available and being used for various purposes at the time in psychology, the discipline from which Scovel and other language researchers were taking their lead. However, what was not clear at the time was that the measures of anxiety that were adapted from psychology for use in language studies had little to do with language itself. (MacIntyre, 2017, n.p)

Within the Specialized Approach, research studies focused on creating a definition for anxiety that would be associated with the process of learning languages. It was during this phase that Horwitz et al. (1986) created the Foreign Language Classroom Anxiety Scale (FLCAS), an instrument to measure levels of FLA that has been used in several studies in the field, and the first anxiety measure tool specifically designed for language learning. According to Dewaele (2017), the major breakthrough of this period in the anxiety studies was the possibility of discerning the construct of language anxiety from the former approach, which was a blend of several kinds of anxiety. The author also claims that it was during this phase that research evidence began to suggest that FLA affects abilities such as listening, speaking, writing and reading in different ways. Finally, in the third phase, the so-called Dynamic Approach, recent studies have included the support of technology (shooting, heart rate monitoring) in the investigation of anxiety within communicational situations. MacIntyre (2017, n.p.) also argue that such modern studies are now situating anxiety among several other factors that influence second language development, such as "linguistic abilities, physiological reactions, self-related appraisals, pragmatics, interpersonal relationships, specific topics being discussed, type of setting in which people are interacting, and so on”.

According to Horwitz et al. (1986), FLA is a specific anxiety reaction. In other words, instead of being anxious in a variety of situations, one normally gets anxious specifically when it comes to learning a new language. The authors describe anxiety as a "subjective feeling of tension, apprehension, nervousness, and worry associated with an arousal of the autonomic nervous system" (p. 125). Many teachers, for instance, have listened to their students claiming to have mental blocks when studying a foreign language. Even though these students may be good learners, they have a strong difficulty to learn a new language because anxiety hinders their performance in class and this negative emotion is unconsciously harming students' performance. MacIntyre and Gregersen (2012, p. 195) claim that language anxiety is "a voluntary and/or involuntary call for help", and when learners face problems in the learning process due to the appearance of negative emotions, teachers have to find resources to convert these feelings into positive emotions.

Some authors have made an attempt to discover which kinds of students suffer from higher levels of anxiety. Horwitz et al. (1986), for instance, argue that people who are anxious in other aspects of their lives tend to be more likely to show anxiety-related difficulties in language learning. Other studies, on the other hand, have demonstrated that there are some specific variables. A study carried out by Dewaele et al. (2016), for instance, found out that female learners experience more FLA, and they are also more affected by both positive and negative emotions (in the classroom) than male peers. In this study, in which items from the FLCAS were also used to measure anxiety levels, 1736 multilinguals were interviewed in order to assess gender differences in foreign language enjoyment and foreign language anxiety. From the results, the authors concluded that female learners worried more about making mistakes and were less confident, but also had more fun in class when compared to male learners. 
Findings from previous research studies seem to suggest that not only internal factors may trigger anxiety in language instruction, but also external factors might be responsible for or at least related to FLA. It is possible, however, that these external factors be soothed by language teachers. For example, a study carried out by Dewaele et al. (2017) found a strong correlation between anxiety and enjoyment in 189 high school students, suggesting that the teachers' attitudes were more related to students' enjoyment than to students' anxiety levels. The authors concluded that it is essential that teachers foster enjoyment in class. That is, creating a good environment for the students, in which they feel comfortable to learn, may contribute to prevent negative emotions in class, decreasing FLA levels. According to the authors, an ideal strategy to deal with anxious learners would be to focus on positive emotions instead of focusing on negative ones.

This conclusion is not far from what Dewaele and Macintyre (2014) found in a study that focused on the relationship between FLA and Foreign Language Enjoyment (FLE). The authors investigated the extent to which levels of anxiety and enjoyment in 1746 learners were linked to variables such as participants' perception of their relative level of proficiency within the foreign language (FL) classroom, number of languages known, level of formal education, number of FLs under study, age group, and general level of proficiency in the FL. Overall, levels of enjoyment were considerably higher than levels of anxiety. Regarding age and FLA, more specifically, the results reported by Dewaele and Macintyre (2014) demonstrate younger learners had higher levels of anxiety. However, we believe these findings are due to the fact that the sampling consisted of very well-educated participants. In their sampling, levels of anxiety decreased in participants who had an MA or PhD diploma. Thus, educational background may overlap with age in this particular context, which would be very unlikely in other contexts where participants do not necessarily advance in education as they get older.

Opposite results are reported in Onwuegbuzie, Bailey and Daley (1999), who designed a study with 210 university students to analyze factors that could predict FLA. A total of seven variables (age, academic achievement, prior history of visiting foreign countries, prior high school experience with foreign languages, expected overall average for current language course, perceived scholastic competence, and perceived self-worth) were investigated and they all were found to predict FLA levels. With respect to age and FLA, in particular, the authors argued that older learners were found to demonstrate higher anxiety levels in comparison to young learners.

In trying to explain the reasons why increasing age could be an aggravating factor in FLA, MacIntyre and Gardner (1994) claim that adult learners normally take longer to process information and are more self-critical on their outcome in terms of accuracy, in comparison to children. Dewaele (2007), on the other hand, argue that young learners may show more anxiety than adults in situations in which language learning is a new experience, that is, in the beginning stages of development.

In sum, the studies presented above (MacIntyre and Gardner, 1994; Onwuegbuzie, Bailey, and Daley, 1999; Dewaele, 2002) have mostly found that more mature learners tended to demonstrate higher levels of anxiety, in comparison to younger learners, with the exception of Dewaele and Macintyre (2014), whose results indicate exactly the opposite. Despite conflicting evidence, research seems to suggest that age is a considerable variable in FLA, but it might overlap with other variables (such as educational background and level of proficiency).

In addition, according to Macintyre (2017), biased perception of proficiency is a cognitive cause for language anxiety. This is reason to believe lower proficiency might be linked to higher levels of anxiety. Moreover, the author considers that misunderstanding communication is also a cause for language anxiety. Therefore, we can imply improving proficiency could alleviate these obstacles and lower one's level of anxiety. Thus, further investigation should be conducted to better understand how age and FLA are related and the extent to which levels of proficiency may be a factor that predicts FLA. This is the empirical gap the present paper aims to fill in. 


\section{Methods}

This study has empirical characteristics. It involved the use of a scale to measure the participant's anxiety levels. This methods section is divided into general and specific objectives, hypotheses, participants, materials, procedures for data collection and analysis. This study was approved by the Ethics Committee under the number CAAE 97908318.4.0000.5347.

\subsection{General objectives}

The prime goal of this research was to investigate the effects of anxiety in instructed foreign language learning. This study focused on variables that can trigger FLA in English learning, more specifically, proficiency and age. Answering this question may help teachers to create strategies that might contribute to create a good environment for students who demonstrate signs of anxiety in their learning process.

\subsection{Specific objectives}

The following were the specific objectives of the present study:

(A) Investigate the relationship between proficiency in the target language and FLA levels.

(B) Investigate the relationship between age and FLA levels.

\subsection{Hypotheses}

The hypotheses below were designed to verify the specific objectives aforementioned:

(A1) The lower the level of proficiency of the participant, the higher would be their scores in the FLA scale. This hypothesis was based on previous studies (MacIntyre and Gardner, 1994) that suggest that more proficient learners may be less affected by FLA.

The participants' proficiency level was obtained through the analysis of the answers given to the self-assessment items in the Language History Questionnaire. It was expected that crossing this information with the results of the FLCAS would show whether participants' proficiency level in the foreign language affected their scores in FLA.

(B1) The older the participant, the higher would be his score in the FLA scale. This hypothesis was based on previous studies (MacIntyre and Gardner, 1994; Onwuegbuzie, Bailey, and Daley, 1999; Dewaele, 2002) which have demonstrated that older learners show higher levels of anxiety,

The participants' age information was also obtained through the Language History Questionnaire. It was expected that crossing this information with the results of the FLCAS would show whether age affected FLA.

\subsection{Participants}

Since the study had the goal of investigating differences between teenagers and adults, it was necessary to find participants who comprised this age range. The teenagers (students from middle and high school) were recruited in a private regular school in the city of Novo Hamburgo, and the adults (English learners) were recruited in a public university in Porto Alegre. In total, 90 learners of English Language participated in the initial sample. All of them had been recruited through spoken invitation before they consented. Only those who met the criteria below were included in the sampling:

- be Brazilian; 
- speak Portuguese as a first language;

- be currently taking English lessons;

The following items were used as exclusion criteria:

- not being Brazilian;

- not speaking Portuguese as a first language;

- people with intellectual or cognitive disability;

It is important to mention that all volunteers who contributed to the research were not paid and were free to withdraw in case they wanted to cancel their participation any time during data collection.

\subsection{Materials}

\subsubsection{Language History Questionnaire (LHQ)}

The Language History Questionnaire - LHQ used in this study was based on the Language Background Questionnaire for Research with Bilinguals, developed by Scholl \& Finger (2013). The questionnaire is divided into three parts. The first one contains questions regarding the participants' education background, in which they are asked to choose the option that represents their schooling level. The second part concerns the environment where the participants learned English; here, participants could choose one or more options that represented where they first learned English (e.g., at home, at school, in a private language course, or others). In the last part, participants assessed their own level of proficiency considering the comprehension skills -listening and reading - as well as production skills -speaking and writing.

\subsubsection{Foreign Language Classroom Anxiety Scale (FLCAS)}

In 1983, beginner students of English were invited to participate in a "Support Group for Foreign Language Learning" at the University of Texas (Horwitz et al., 1986). Two groups were formed to attend meetings where they would discuss concerns and difficulties related to language learning. This experiment resulted in the creation of the Foreign Language Classroom Anxiety Scale, a questionnaire that measures the level of Foreign Language Anxiety in a classroom through thirty-three questions. These questions are divided into three categories: Communication apprehension (eleven questions), Fear of feedback by peers and teachers (seven questions), and Fear of language tests (fifteen questions). Below are examples of sentences from the three categories of items:

\section{Communication apprehension:}

"I never feel quite sure of myself when I am speaking in my foreign language class."

"It frightens me when I don't understand what the teacher is saying in the foreign language."

Fear of feedback by peers and teachers:

"I don't worry about making mistakes in language class."

"I keep thinking that the other students are better at languages than I am."

Fear of language tests:

"It wouldn't bother me at all to take more foreign language classes."

"I worry about the consequences of failing my foreign language class." 
In the FLA scale, participants are asked to read the statements and choose in a Likert scale from five options, that include Strongly agree; Agree; Neither agree nor disagree; Disagree; Strongly disagree. The results classify learners as showing 1) a low level of anxiety, 2) a medium level of anxiety, or 3) a high intensity anxiety. Since the participants of the present study range from beginners to advanced students, the scale was translated into Brazilian Portuguese. In order to make sure the translation did not remove the gist of the original scale, two proficient English speakers made a back translation.

\subsection{Procedures for data collection}

The tasks were applied in a sequential order. First, the participants or their parents (in the case of underaged students) signed the Informed Consent Form. Soon after, participants answered the Language History Questionnaire, used to obtain student's background information, such as age and self-assessed proficiency. Finally, they were asked to answer the FLCAS, which measured their anxiety levels. On the day of data collection, decided in agreement with the coordination (at school) and professors (at university), students received all documents printed and filled them out manually.

\subsection{Procedure for data analysis}

Once all data was collected, the information was manually inserted in an Excel spreadsheet in the following order: number, name, age, total score, anxiety level, and group. The FLCAS gives the result as a total score ranging from 33 to 165, so the total scores from each participant were classified as follows, on the basis of the calculation proposed by Horwitz et al. (1986).

Table 1: Scoring of the answers in the FLCAS

\begin{tabular}{|c|c|}
\hline Score & Classification \\
\hline $33-75$ (low) & 1 \\
\hline $76-119$ (medium) & 2 \\
\hline Above 120 (high) & 3 \\
\hline
\end{tabular}

Later on, all data was transposed to the software SPSS, in which the analysis of the information obtained in the LHQ and in the FLCAS was conducted in order to verify the objectives.

\section{Data analysis and discussion}

After applying the exclusion criteria, 88 participants were included in the final sample. The sampling consisted of 23 male (26.1\%) and 65 female (73.9\%) participants. Mean age was 18.81 (SD: 4.328). All of them self-evaluated their proficiency levels in English considering listening, reading, speaking and writing. They were asked to self-evaluate each ability from 1 to 6 . The lumpsum was divided by four so each participant would have a mean proficiency also ranging from 1 to 6. One of the problems was that, due to reasons we can only presume, participants with lower levels of proficiency did not differentiate much from participants with higher levels of proficiency (considering mean proficiency). Perhaps they either did not know how to accurately evaluate their proficiency, or they did not feel comfortable to answer honestly. Even though a higher difference between the participants' proficiency levels was expected to be found, this did not compromise the results of the study.

The first specific objective of this study was to investigate the relationship between proficiency in the target language and FLA levels. As previously stated, the participants' proficiency 
level was obtained through the answers given to the self-assessment items in the Language History Questionnaire. On the basis of previous studies (MacIntyre and Gardner, 1994), it was expected that the lower the proficiency level of the participant, the higher would be their scores in the FLA scale, a hypothesis which was supported by the results found. A Pearson correlation analysis of the data gathered through the LHQ and the FLCAS revealed a significant negative correlation between mean proficiency and the level of anxiety $(r=-0.390 ; p=0.000)$. In other words, the results obtained indicated that the lower the participant's proficiency level, the higher their level of anxiety as demonstrated in the scale.

The second specific objective of this study was to investigate the relationship between age and FLA. The participants' age information was obtained through the answers given in the Language History Questionnaire. The hypothesis, which predicted that the older the participant, the higher would be his score in the FLA scale, was also supported by the results found, confirming what was reported in previous studies (MacIntyre and Gardner, 1994; Onwuegbuzie, Bailey, and Daley, 1999; Dewaele, 2002). A Pearson correlation analysis of the data related to age and levels of anxiety revealed a significant positive correlation $(r=0.026 ; p=0.035)$. This result means that the older the participant, the higher their anxiety level as demonstrated in the scale.

The results found in this study seem to suggest that both older and beginner learners of English are more affected by FLA than younger and more advanced learners, respectively. This may be due to the fact that adults have less time to practice the target language when compared to teenagers and are usually impatient and in a hurry to see results; therefore, they are more likely to have negative emotions (such as anxiety) towards the whole learning process. As Fredrickson (2004) stated, positive emotions improve one's cognition and attention, so it is likely that beginners lack this advantage. They might be less confident due to the fact that they do not yet master the language, as suggested by MacIntyre and Gardner (1994). The statistical analysis of the data demonstrate that more proficient learners showed lower levels of anxiety, possibly because higher proficiency boosts their confidence; reducing anxiety levels as a consequence. However, as they advance in learning, we can assume that anxiety tends to reduce. Therefore, the results of the present study are consistent with previous investigations that have revealed an important role for age and proficiency in the levels of FLA.

Finally, in what regards age, as mentioned in the literature review of this article, López and Aguilar (2013) state that previous bad experiences hinder the foreign language learning process. Thus, older learners have probably endured more time exposed to either bad environments for learning or frustrating attempts of learning, which might have prevented them from creating psychological resources to deal with the learning process, resulting in higher levels of anxiety. These are all, of course, assumptions. More detailed research on external factors would be necessary to better understand all the variables that have led to these results.

\section{Final considerations}

The goal of the present study was to investigate the relationship between foreign language anxiety (FLA) and two specific individual variables: proficiency and age. The findings of this study suggest that both older and beginner learners of English are more affected by FLA than young and more advanced learners, respectively. What motivated the research in the first place was mainly the possibility of thinking about new approaches to deal with anxiety in the classroom. Therefore, we expect that these results will provide a contribution so that teachers can create strategies that might contribute to ensure a good environment for students who demonstrate signs of anxiety in their learning process. Hopefully, this will be a starting point for future research studies on emotions and language learning in Brazil.

At the end of the analyses, we wondered whether we were trying to calculate something that cannot be mathematically analyzed: emotions, which took us back to what Dewaele et al. (2017) 
argue about how to deal with anxiety in the classroom. According to the authors, teachers should work more towards the arousal of positive emotions rather than focusing on negative ones. Therefore, the most important pedagogical implication this study brings is the endorsement of the teacher's role as an agent who should foster positive emotions in the classroom. Pekrun (2014) claims that teachers are able to help students develop self-confidence and reduce negative emotions through high-quality instructions and should be careful with the peer climate in the classroom, for example. The author also suggests that teachers should use their own emotional experiences to better understand students, as seen below:

Positive teacher emotions can promote students' enjoyment of learning within the classroom and can have long-lasting effects on the value of learning perceived by students. Therefore, teachers should take care to show the positive emotions they feel about teaching and the subject matter, and make sure that they share positive emotions and enthusiasm with their students. (Pekrun, 2014, p. 21)

Having in mind that focusing on positive emotions is the best answer for now, the next step should be identifying how to foster positive emotions during language instruction. The future is positive.

\section{References}

AMERICAN PSYCHIATRIC ASSOCIATION. Diagnostic and Statistical Manual of Mental Disorders. 5. ed. Arlington: American Psychiatric Association, 2013.

CRASKE, M.G.; RAUCH, S.; ZINBARG, R. What is an anxiety disorder? Depression and Anxiety, v. 26, n.12, pp. 1066-1085, 2009.

DEWAELE, J-M. Psychological and sociodemographic correlates of communicative anxiety in L2 and L3 production. International Journal of Bilingualism, v.6, n.1, pp. 23-38, 2002.

DEWAELE, J-M. Psychological Dimensions and Foreign Language Anxiety. In: LOEWEN, S.; SATO, M. (Eds.) The Routledge Handbook of Instructed Second Language Acquisition. London: Routledge, 2017. pp. 433-450.

DEWAELE, J-M.; DEWAELE, L. The dynamic interactions in foreign language classroom anxiety and foreign language enjoyment of pupils aged 12 to 18 . A pseudo-longitudinal investigation. Journal of The European Second Language Association, v. 1, n. 1, pp.12-22, 2017.

DEWAELE, J-M.; MACINTYRE, P.; BOUDREAU, C.; DEWAELE, L. et al. Do Girls Have All the Fun? Anxiety and Enjoyment in the Foreign Language Classroom. Theory and Practice of Second Language Acquisition, v. 2, n. 1, pp.41-63, 2016.

DEWAELE, J-M.; MERCER, S. Variation in ESL/EFL teachers' attitudes towards their students. In: MERCER, S.; KOSTOULAS, A. (Ed.). Language Teacher Psychology. Bristol: Multilingual Matters, 2018. pp. 178-195.

DEWAELE, J-M.; WITNEY, J.; SAITO, K.; DEWAELE, L. Foreign language enjoyment and anxiety: The effect of teacher and learner variables. Language Teaching Research, v.22, n.6, pp. 676697, 2017.

FREDRICKSON, B. The broaden-and-build theory of positive emotions. Philosophical Transactions of the Royal Society: Biological Sciences, v.359, n.1449, pp.1367-1377, 2004.

GARDNER, H.; LAMBERT, W.E. Attitudes and motivation in second language learning. Rowley, MA: Newbury House, 1972.

HORWITZ, E. K.; HORWITZ, M. B.; COPE, J. Foreign Language Classroom Anxiety. The Modern Language Journal, v. 70, n. 2, pp.125-132, 1986. 
ISMAIL, N.M. EFL Saudi Students' Class emotions and their contributions to their English achievement at Taif University. International Journal of Psychological Studies, v. 7, n. 4, pp.19-42, 2015.

KHAJAVY, G.H.; MACINTYRE, P.D.; BARABADI, E. Role of the emotions and classroom environment in willingness to communicate: applying doubly latent multilevel analysis in second language acquisition research. Studies in Second Language Acquisition, v.40, n.3, pp.605-624, 2017.

MACINTYRE, P.D. An overview of language anxiety research and trends in its development. In: GKONOU, C.; DAUBNEY, M.; DEWAELE, J-M. (Ed.). New insights into language anxiety: Theory, research and educational implications. Bristol: Multilingual Matters, 2017. pp.11-30.

MACINTYRE, P.D.; GARDNER, R. The Subtle Effects of Language Anxiety on Cognitive Processing in the Second Language. Language Learning, v.44, pp.283-305, 1994. http://dx.doi.org/10.1111/j.1467-1770.1994.tb01103.x

MACINTYRE, P.D.; GREGERSEN, T. Emotions that facilitate language learning: The positivebroadening power of the imagination. Studies in Second Language Learning and Teaching, v. 2, n. 2, pp.193-213, 2012.

MÉNDEZ LÓPEZ, M.G.; AGUILAR, A.P. Emotions as Learning Enhancers of Foreign Language Learning Motivation. Profile: Issues in Teachers' Professional Development, Bogotá, v. 15, n. 1, pp.109124, 2013.

ONWUEGBUZIE, A.; BAILEY, P.; DALEY, C.E. Factors associated with foreign language anxiety. Applied Psycholinguistics, v. 20, n.2, pp. 217-239, 1999. doi:10.1017/S0142716499002039

OXFORD, R.L. Anxiety and the Language Learner: New Insights. In: MORGAN, Jane Arnold (Ed.). Affect in language learning. Cambridge, MA: Cambridge University Press, 1999. pp.58-67.

PEKRUN, R. Emotions and learning. Switzerland: Unesco International Bureau of Education, 2014. 32 p. Available on: <https://unesdoc.unesco.org/ark:/48223/pf0000227679>. Access: 10 jun. 2019.

SCHOLL, A.P.; FINGER, I. Elaboração de um questionário de histórico da linguagem para pesquisas com bilíngues. Nonada: Letras em Revista, v. 2, n. 21, 2013.

SILVERMAN, W.K.; FIELD, A.P. (Ed.). Anxiety Disorders in Children and Adolescents. 2. ed. Cambridge: Cambridge University Press, 2001.

Recebido em: 14/11/19

Aceito em: 29/11/19 